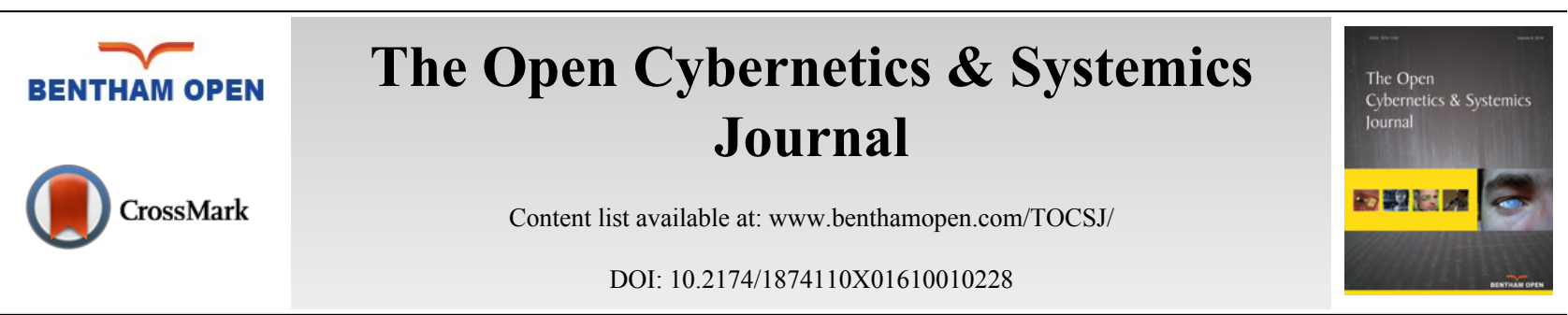

RESEARCH ARTICLE

\title{
Improved Backstepping Adaptive Control of Dual-motor Driving Servo System with Backlash Based on Fuzzy Parameter Approximation
}

\author{
Haibo Zhao ${ }^{1, *}$ and Chengguang Wang ${ }^{2}$ \\ ${ }^{I}$ School of Electrical Engineering and Engineering Technology Research Center of Optoelectronic Appliance, Tongling \\ University, Tongling 244061, PR China \\ ${ }^{2}$ Sichuan Institute of Aerospace System Engineering, Sichuan 610100, PR China
}

Received: July 03, 2016

Revised: August 15, 2016

Accepted: September 16, 2016

\begin{abstract}
Aiming at the control problem of dual-motor driving servo system with backlash nonlinearity, a model for the system is introduced. Two adaptive fuzzy systems were used to approximate the nonlinear part and unknown parameters in system online, to avoid the complex calculation in deducing the adaptive law of each unknown parameter. By using improved backstepping approach and recursively selecting the Lyapunov function, introducing the virtual control quantity and the integration of position tracking error, an adaptive fuzzy controller with state feedback was designed, and its stability was analyzed. System response analysis and system robustness analysis were considered in simulation test for comparing the improved backstepping control with conventional backstepping control. Simulation results show that the improved backstepping control has better position tracking performance and robustness than conventional backstepping control. Finally, experimental analysis also validates the effectiveness and efficiency of the proposed control strategy.
\end{abstract}

Keywords: Backstepping adaptive control, Backlash nonlinearity, Dual-motor driving, Fuzzy approximation system, Robustness.

\section{INTRODUCTION}

Backlash nonlinearity widely exists in artillery turret system, radar, machine tools, robots, etc. In mechanical transmission system, the existence of backlash nonlinearity affects the dynamic performance and steady state accuracy of system [1]. Simultaneously, the mutual collision of gears can also produce severe oscillation and noise [2]. Hence, in order to weaken the adverse effect of backlash nonlinearity on system, the control strategy of backlash nonlinearity should be studied, which has important theoretical significance and engineering application value.

In domestic and foreign research results, a variety of nonlinear models have been established according to the different characteristics of backlash nonlinear, mainly including the hysteretic model [3], the dead-zone model [4, 5], and the impact model [6]. On the other hand, the control methods of system with backlash are being frequently developing, such as adaptive inverse method [7, 8], robust adaptive control [9 - 11], fuzzy logic control [12, 13], neural network control $[14,15]$ and so on. In recent years, backlash nonlinearity compensation strategies have also been studied by many scholars. Jozef [16] adopted a three-block cascade model to identify the parameters of nonlinear dynamic systems with input saturation and output backlash. In [17], aiming at a class of periodically time-varying systems with input backlash, an adaptive controller is designed. In [18], for a class of time-varying nonlinear systems with input backlash, an iterative learning control method is proposed. In [19], a nonlinear control system considering the uncertainties of the backlash of nonlinear plants is proposed. A robust nonlinear control system is designed. The

\footnotetext{
* Address correspondence to this author at the School of Electrical Engineering and Engineering Technology Research Center of Optoelectronic Appliance, Tongling University, Tongling, 244061, PR China; Tel: +86-13866506742; E-mail: happyzhaohaibo@126.com
} 
effectiveness of the proposed system is confirmed by simulations. In [20], by applying the ER damper to the DD motor system, it is possible to obtain mechanical damping and to realize a high servo gain in the motion control. And the effectiveness of the proposed system is confirmed experimentally. In [21], a new switched reluctance motor for hybrid motion control is presented. Accordance of experimental values with the FEA results certifies the performance and applicability of the motor. However [16 - 21], backstepping control strategy has not been used.

Backstepping adaptive control has the features of simple algorithm and strong robustness, and has been applied successfully in some practical industries and aerospace control systems, the algorithm itself has high maturity. In [22], a double degree freedom backstepping control method is proposed for position tracking of rocket launcher. The simulation and experiment results show that the proposed approach can guarantee the response speed and control accuracy and has a strong robustness for the load disturbance and parameter perturbation. In [23], a backstepping controller is proposed for blended control missile. Simulation results demonstrate the superiority and effectiveness of the control scheme. Geng Bao-Liang, et al. [24] investigated the prescribed performance backstepping control problem for a class of uncertain strict-feedback nonlinear systems whose control gains are unknown functions. The designed controller guarantees that the prescribed transient and steady state error bounds are satisfied and all state variables are bounded. The effectiveness of the proposed scheme is validated by simulation. Zong Q, et al. [25] designed a robust adaptive backstepping control scheme of flexible air-breathing hypersonic vehicle with input constraint and aerodynamic uncertainty. The simulation results validate the effectiveness of proposed control strategy. However, all the backstepping control strategies used in [22 - 25] are conventional. In addition, backstepping control is rarely used alone, and is usually used in conjunction with other control methods. In [26 - 28], backstepping control in conjunction with fuzzy control, namely backstepping fuzzy control, has been successfully applied in nonlinear system. But the controlled object is not dual-motor driving servo system. In [5], backstepping control has been used in servo system with backlash, but the servo system is single-motor driving system and the backstepping algorithm is also conventional. Moreover, single-motor driving system has been unable to meet the needs of many high-power occasions.

In this paper, aiming at the dual-motor driving servo system, an improved backstepping control strategy is proposed introducing the integration of position tracking error so as to ensure system tracking error asymptotically stable which tends to zero better under the condition of uncertain system model. Two fuzzy approximation systems are introduced in the process of designing backstepping controller, which not only saves the trouble of deducing the adaptive law of each unknown parameter, but also avoids the problem of multiple derivations in backstepping design, weakening greatly the complexity of the controller design.

This paper is organized as follows: system modeling is given in Section 2. The design of backstepping controller is presented in Section 3. Simulation analysis and experimental analysis in Section 4 and Section 5 to show the effectiveness of the proposed strategy. Section 6 concludes this paper.

\section{SYSTEM MODELING}

The schematic diagram of dual-motor driving servo system is shown in Fig. (1). $O_{0}$ is driven-subsystem, $\mathrm{O}_{1}$ and $\mathrm{O}_{2}$ are driving-subsystems.

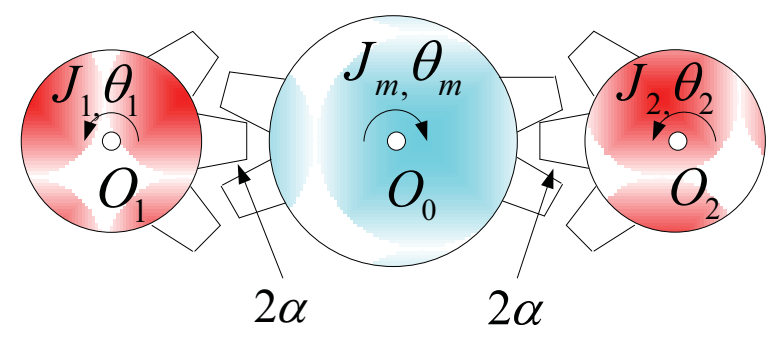

Fig. (1). The schematic diagram of dual-motor driving servo system.

Assumption 1: In the control process, driven-subsystem $O_{0}$ contacts with $O_{1}$ and $O_{2}$ alternatively. It was guaranteed by exerting two bias torques on $O_{0}$ from the output terminal of $O_{1}$ and $O_{2}$ respectively. The bias torques are equal and opposite. The block diagram of dual-motor driving servo system is shown in Fig. (2). 


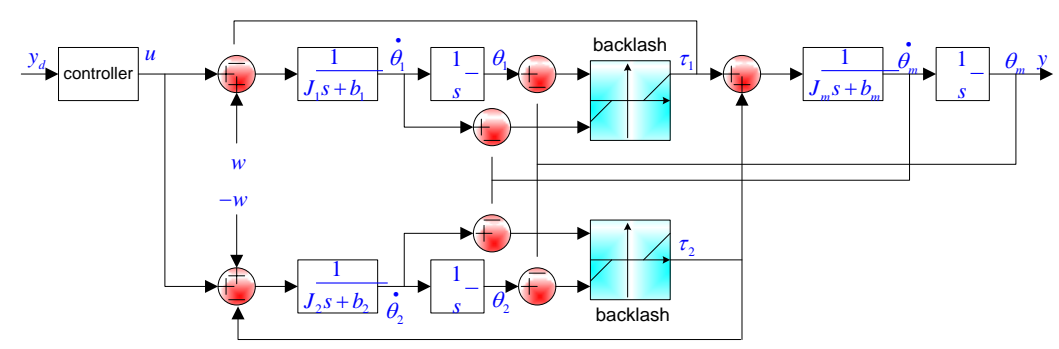

Fig. (2). The block diagram of dual-motor driving servo system.

According to [29], the state equation of system can be expressed as follows:

$$
\left\{\begin{array}{l}
\dot{x_{1}}=x_{2} \\
\dot{x_{2}}=-a_{1} x_{2}+a_{3} \sum_{i=1}^{2} \tau_{i} \\
\dot{x_{3 i}}=x_{4 i} \\
\dot{x_{4 i}}=-a_{0} x_{3 i}-\left(a_{0}-a_{1}\right) x_{2} \rho+a_{2}\left(u(t)-(-1)^{i} w\right) \rho \\
\quad-\left(a_{2}+a_{3}\right) \tau_{i} \rho+8 r^{2} \alpha \dot{z}_{i} \varpi \\
y=x_{1}
\end{array}\right.
$$

where

$$
a_{0}=\frac{b_{i}}{J_{i}}, \quad a_{1}=\frac{b_{m}}{J_{m}}, \quad a_{2}=\frac{1}{J_{i}}, \quad a_{3}=\frac{1}{J_{m}}, \quad \rho=1-8 r \alpha \frac{e^{-r \alpha}}{\left(1+e^{-r z_{i}}\right)^{2}}, \quad \varpi=\frac{e^{-r z_{i}}\left(1-e^{-r z_{i}}\right)}{\left(1+e^{-r z_{i}}\right)^{3}}
$$

In practical system, $\mathrm{J}_{\mathrm{i}}, \mathrm{J}_{\mathrm{m}}, \mathrm{b}_{\mathrm{i}}, \mathrm{b}_{\mathrm{m}}, \mathrm{k}$ and $\mathrm{c}$ are uncertain because they are affected by temperature, lubrication and material wear. They are all regarded as unknown parameters in the process of controller design. The goal of this paper is to design adaptive controller so as to make system output y asymptotically stable tracking the expected output $\mathrm{y}_{\mathrm{d}}$, namely $\lim _{t \rightarrow \infty}\left|y-y_{d}\right|=0$.

\section{BACKSTEPPING ADAPTIVE CONTROL BASED ON FUZZY PARAMETER APPROXIMATION}

From eqs.(1), it can be seen that $O_{1}$ and $O_{2}$ are parallel relationship, and they are connected in series with $O_{0}$. In this section, the control variable of each subsystem is recursively selected by backstepping control strategy. Two fuzzy logic systems are used to approximate nonlinear component including unknown parameters.

Assumption 2: System parameters $\theta_{i}(t), \theta_{m}(t), \dot{\theta}_{i}(t)$ and $\dot{\theta}_{m}(t)$ are all measurable.

Assumption 3: Parameters $\mathrm{J}_{\mathrm{i}}, \mathrm{J}_{\mathrm{m}}, \mathrm{k}$ and $\mathrm{c}$ are bounded:

$0<\mathrm{J}_{\mathrm{i} \text { min }} \leq \mathrm{J}_{\mathrm{i}} \leq \mathrm{J}_{\mathrm{i} \max }, 0<\mathrm{J}_{\mathrm{m} \min } \leq \mathrm{J}_{\mathrm{m}} \leq \mathrm{J}_{\mathrm{m} \max }, 0<\mathrm{k}_{\min } \leq \mathrm{k} \leq \mathrm{k}_{\max }, 0<\mathrm{c}_{\min } \leq \mathrm{c} \leq \mathrm{c}_{\max }$.

Assumption 4: If $z_{i}(t)$ is bounded, then $x_{3 i}$ and $x_{4 i}$ are all bounded. Suppose $x_{3 i \min } \leq x_{3 i} \leq x_{3 i \max }, x_{4 i \min } \leq x_{4 i} \leq x_{4 i \max }$.

\subsection{Fuzzy Approximation System}

In order to not only satisfy the adaptive unknown parameters and the tracking accuracy of system, but also to avoid the complex calculation of each parameter's adaptive law in backstepping process, two adaptive fuzzy systems are employed to approximate the nonlinear part in system [30].

Using the following fuzzy system:

$$
f(x)=\sum_{l=1}^{M} \xi_{l}(x) \theta_{l}=\theta^{T} \xi(x)
$$


where $\mathrm{f}(\mathrm{x})$ is the output of fuzzy system, $\mathrm{x}^{\mathrm{T}}=\left(\mathrm{x}_{1}, \mathrm{x}_{2}, \ldots, \mathrm{x}_{\mathrm{n}}\right)^{\mathrm{T}}$ is the input of fuzzy system, $\mathrm{M}$ is the total number of fuzzy rules, $\theta=\left(\theta_{1}, \theta_{2}, \ldots, \theta_{n}\right)^{\mathrm{T}}$ is adjustable parameter vector, $\xi^{\mathrm{T}}(\mathrm{x})=\left(\xi_{1}(\mathrm{x}), \xi_{2}(\mathrm{x}), \ldots, \xi_{\mathrm{n}}(\mathrm{x})\right)^{\mathrm{T}}$ is fuzzy basis function, its definition is as follows:

$$
\xi_{l}(x)=\frac{\prod_{i=1}^{n} \mu_{A_{i}^{l}}\left(x_{i}\right)}{\sum_{l=1}^{M} \prod_{i=1}^{n} \mu_{A_{i}^{l}}\left(x_{i}\right)}
$$

where $\mu_{A_{i}^{l}}\left(x_{i}\right)$ is membership function. By the almighty approaching theorem, it can be seen that this fuzzy system can approximate any degree of accuracy to any continuous function in a compact domain.

\subsection{Controller Design}

Step 1: Define position tracking error $\mathrm{e}_{1}$ as:

$$
e_{1}=y-y_{d}=x_{1}-y_{d}
$$

where $y_{d}=\theta_{d}^{*}(t)$ is desired position output.

The derivative of $\mathrm{e}_{1}$ is:

$$
\dot{e}_{1}=\dot{x}_{1}-\dot{y}_{d}=x_{2}-\dot{y}_{d}
$$

Choose the following control Lyapunov function(CLF):

$$
V_{1}=\frac{1}{2} e_{1}^{2}
$$

Its derivative is:

$$
\dot{V}_{1}=e_{1} \dot{e}_{1}=e_{1}\left(x_{2}-\dot{y}_{d}\right)
$$

Let $\mathrm{e}_{2}$ be virtual control variable, suppose the expectation of $\mathrm{x}_{2}$ is $\eta_{1}$, define the error between $\mathrm{x}_{2}$ and $\eta_{1}$ is $\mathrm{e}_{2}$, namely:

$$
e_{2}=x_{2}-\eta_{1}
$$

if,

$$
\eta_{1}=-k_{1} e_{1}+\dot{y}_{d}-k_{0} \int_{0}^{t} e_{1}(\tau) d \tau
$$

then,

$$
\dot{V}_{1}=e_{1}\left(e_{2}+\eta_{1}-\dot{y}_{d}\right)=e_{1}\left(e_{2}-k_{1} e_{1}+\dot{y}_{d}-k_{0} \int_{0}^{t} e_{1}(\tau) d \tau-\dot{y}_{d}\right)=-k_{1} e_{1}^{2}+e_{1} e_{2}-k_{0} e_{1} A
$$

where $k_{0}>0, \mathrm{k}_{1}>0$ are adjustable parameters, A is the integral of position tracking error, $A=\int_{0}^{t} e_{1}(\tau) d \tau \ldots$

The purpose of $\mathrm{A}$ is to ensure that system position tracking error which is asymptotically stable can tend to zero under the condition of uncertain system model.

Step 2: Let $\mathrm{x}_{31}+\mathrm{x}_{32}$ be virtual control variable, augmented CLF $\mathrm{V}_{2}$ can be chosen as follows.

$$
V_{2}=V_{1}+\frac{J_{m}}{2 k} e_{2}^{2}+\frac{1}{2} k_{0} A^{2}
$$

Its derivative is: 


$$
\dot{V}_{2}=\dot{V}_{1}+\frac{J_{m}}{k} e_{2} \dot{e}_{2}+k_{0} A e_{1}(t)=-k_{1} e_{1}^{2}+e_{2}\left[\sum_{i=1}^{2} x_{3 i}-\frac{b_{m}}{k} x_{2}-\frac{J_{m}}{k} \dot{\eta}_{1}+e_{1}+\frac{c}{k} \sum_{i=1}^{2} x_{4 i}\right]=-k_{1} e_{1}^{2}+e_{2}\left[\sum_{i=1}^{2} x_{3 i}-N_{1}+\frac{c}{k} \sum_{i=1}^{2} x_{4 i}\right]
$$

According to assumption $3 \sim 4$, it can be seen that:

$$
\frac{c}{k} \sum_{i=1}^{2} x_{4 i} \leqslant \frac{2 c_{\max }}{k_{\min }} x_{4 i \max }=d_{1}
$$

where $d_{1}>0$ is a constant.

In eqs.(4), nonlinear function $\mathrm{N}_{1}$ is:

$$
N_{1}=\frac{b_{m}}{k} X_{2}+\frac{J_{m}}{k} \dot{\eta}_{1}-e_{1}
$$

$\mathrm{N}_{1}$ contains unknown parameters $\mathrm{b}_{\mathrm{m}}, \mathrm{J}_{\mathrm{m}}, \mathrm{k}$, an adaptive fuzzy system is available to approach them:

$$
N_{1}=\theta_{1}^{* \mathrm{~T}} \xi\left(\bar{e}_{1}\right)+\varepsilon_{1}
$$

where $\theta_{1}^{*}$ is ideal approximation parameter, $\varepsilon_{1}$ is minimum approximation error, $\overline{\mathrm{e}}_{1}=\left(\mathrm{e}_{1}, \mathrm{e}_{2}\right)^{\mathrm{T}}$ is the input error vector of fuzzy system.

Suppose the expectation of $x_{31}+x_{32}$ is $\eta_{2}$, define error variable $e_{3}$ as follows:

$$
e_{3}=x_{31}+x_{32}-\eta_{2}
$$

if,

$$
\eta_{2}=\hat{\theta}_{1}^{\mathrm{T}} \xi\left(\overline{e_{1}}\right)-k_{2} e_{2}-\frac{d_{1}^{2} e_{2}}{4 \varepsilon_{d 1}}
$$
$\varepsilon_{\mathrm{d} 1}>0$.

where $\hat{\theta}_{1}$ is fuzzy estimate parameter, $k_{2}^{\prime}=k_{2}+\frac{d_{1}^{2}}{4 \varepsilon_{d 1}}>0$ is adjustable parameter, $-\frac{d_{1}^{2} e_{2}}{4 \varepsilon_{d 1}}$ is robust control term,
$>0$.

Then we can get:

$$
e_{2}\left[-\frac{d_{1}^{2} e_{2}}{4 \varepsilon_{d 1}}+\frac{c}{k} \sum_{i=1}^{2} x_{4 i}\right] \leqslant-\frac{d_{1}^{2} e_{2}^{2}}{4 \varepsilon_{d 1}}+\left|e_{2}\right| d_{1} \leqslant \varepsilon_{d 1}
$$

Substituting eqs.(5-8) into eq.(4), we can get:

$$
\dot{V}_{2} \leqslant-k_{1} e_{1}^{2}-k_{2} e_{2}^{2}+e_{2} e_{3}+e_{2}\left[\tilde{\theta}_{1}^{\mathrm{T}} \xi\left(e_{1}\right)-\varepsilon_{1}\right]+\varepsilon_{d 1}
$$

where $\tilde{\theta}_{1}^{\mathrm{T}}=\hat{\theta}_{1}^{\mathrm{T}}-\theta_{1}^{* \mathrm{~T}}$ is the parameter estimation error.

Step 3: Let $\mathrm{x}_{41}+\mathrm{x}_{42}$ be virtual control variable, augmented CLF $\mathrm{V}_{3}$ can be chosen as follows:

$$
V_{3}=V_{2}+\frac{1}{2} e_{3}^{2}
$$

Its derivative is,

$$
\dot{V}_{3} \leqslant-k_{1} e_{1}^{2}-k_{2} e_{2}^{2}+e_{2}\left[\tilde{\theta}_{1}^{\mathrm{T}} \xi\left(\bar{e}_{1}\right)-\varepsilon_{1}\right]+e_{3}\left(e_{2}+x_{41}+x_{42}-\dot{\eta}_{2}\right)+\varepsilon_{d 1}
$$


Suppose the expectation of $\mathrm{x}_{41}+\mathrm{x}_{42}$ is $\eta_{3}$, define error variable $\mathrm{e}_{4}$ as follows:

$$
e_{4}=x_{41}+x_{42}-\eta_{3}
$$

if,

$$
\eta_{3}=-k_{3} e_{3}-e_{2}+\dot{\eta}_{2}
$$

where $\mathrm{k}_{3}>0$ is adjustable parameter.

then we can get eq.(13) after substituting eqs.(11), (12) into eq.(10).

$$
\dot{V}_{3} \leqslant-k_{1} e_{1}^{2}-k_{2} e_{2}^{2}-k_{3} e_{3}^{2}+e_{3} e_{4}+e_{2}\left[\tilde{\theta}_{1}^{\mathrm{T}} \xi\left(\bar{e}_{1}\right)-\varepsilon_{1}\right]+\varepsilon_{d 1}
$$

Step 4: We chose augmented CLF $\mathrm{V}_{4}$ as follows:

$$
V_{4}=V_{3}+\frac{J_{1} J_{2}}{2\left(J_{1}+J_{2}\right)} e_{4}^{2}
$$

Its derivative is,

$$
\dot{V}_{4} \leqslant-k_{1} e_{1}^{2}-k_{2} e_{2}^{2}-k_{3} e_{3}^{2}+e_{2}\left[\tilde{\theta}_{1}^{\mathrm{T}} \xi\left(\bar{e}_{1}\right)-\varepsilon_{1}\right]+\varepsilon_{d 1}+e_{4} \times\left[\rho u(t)-N_{2}-\frac{J_{1} J_{2}}{J_{1}+J_{2}} \sum_{i=1}^{2}\left(\frac{\rho k\left(J_{i}+J_{m}\right)}{J_{i} J_{m}} x_{3 i}\right)\right]
$$

According to assumption 3 4, it can be seen that:

$$
\frac{J_{1} J_{2}}{J_{1}+J_{2}} \sum_{i=1}^{2}\left(\frac{\rho k\left(J_{i}+J_{m}\right)}{J_{i} J_{m}} x_{3 i}\right) \leqslant k_{\max } \frac{J_{i \max }^{2}\left(J_{i \max }+J_{m \max }\right)}{J_{i \min }^{2} J_{m \min }} \times x_{3 i \max }=d_{2}
$$

where $|\rho|<1, \mathrm{~d}_{2}>0$ is a constant.

In eq.(14), nonlinear function $\mathrm{N}_{2}$ is:

$$
N_{2}=\frac{J_{1} J_{2}}{J_{1}+J_{2}}\left(\sum_{i=1}^{2}\left(\frac{\rho c\left(J_{i}+J_{m}\right)}{J_{i} J_{m}} x_{4 i}\right)+\sum_{i=1}^{2} \frac{b_{i}}{J_{i}} x_{3 i}+\sum_{i=1}^{2}\left(\frac{b_{i}}{J_{i}}-\frac{b_{m}}{J_{m}}\right) \rho x_{2}-\left(\frac{J_{2}-J_{1}}{J_{1} J_{2}}\right) w \rho-16 r^{2} \alpha \dot{z}_{i} \varpi-\dot{\eta}_{3}-e_{3}\right)
$$

$\mathrm{N}_{2}$ contains unknown parameters $\mathrm{b}_{\mathrm{m}}, \mathrm{J}_{\mathrm{m}}, \mathrm{b}_{\mathrm{i}}, \mathrm{J}_{\mathrm{i}}, \mathrm{c}$, an adaptive fuzzy system is available to approach them:

$$
N_{2}=\theta_{2}^{* \mathrm{~T}} \xi\left(\bar{e}_{2}\right)+\varepsilon_{2}
$$

where $\theta_{2}^{*}$ is ideal approximation parameter, $\varepsilon_{2}$ is minimum approximation error, $\overline{\mathrm{e}}_{2}=\left(\mathrm{e}_{3}, \mathrm{e}_{4}\right)^{\mathrm{T}}$ is the input error vector of fuzzy system.

If we choose control input $u(t)$ and the adaptive law of $\hat{\theta}_{1}, \hat{\theta}_{2}$ as follows:

$$
\begin{gathered}
u(t)=\frac{1}{\rho}\left[\hat{\theta}_{2}^{\mathrm{T}} \xi\left(\bar{e}_{2}\right)-k_{4} e_{4}-\frac{d_{2}^{2} e_{4}}{4 \varepsilon_{d 2}}\right] \\
\hat{\hat{\theta}}_{1}=\Gamma_{1} \xi\left(\overline{e_{1}}\right) e_{2}-2 \hat{\theta}_{1} \\
\dot{\hat{\theta}}_{2}=\Gamma_{2} \xi\left(\overline{e_{2}}\right) e_{4}-2 \hat{\theta}_{2}
\end{gathered}
$$

where $\hat{\theta}_{1}, \hat{\theta}_{2}$ are fuzzy estimate parameters, $k_{4}^{\prime}=k_{4}+\frac{d_{2}^{2}}{4 \varepsilon_{d 2}}>0$ is adjustable parameter, $-\frac{d_{2}^{2} e_{4}}{4 \varepsilon_{d 2}}$ is robust control 
term, $\varepsilon_{d 2}>0, \Gamma_{1}$ and $\Gamma_{2}$ are all positive definite diagonal matrixes.

Then in the same way as eq.(13), we have:

$$
e_{4}\left[-\frac{d_{2}^{2} e_{4}}{4 \varepsilon_{d 2}}-\rho k\left(1+\frac{J_{i}}{J_{m}}\right) \sum_{i=1}^{2} x_{3 i}\right] \leqslant-\frac{d_{2}^{2} e_{4}^{2}}{4 \varepsilon_{d 2}}+\left|e_{4}\right| d_{2} \leqslant \varepsilon_{d 2}
$$

Substituting eqs.(15), (16), (19) into eq.(14), we can get:

$$
\dot{V}_{4} \leqslant-k_{1} e_{1}^{2}-k_{2} e_{2}^{2}-k_{3} e_{3}^{2}-k_{4} e_{4}^{2}+e_{2}\left[\tilde{\theta}_{1}^{\mathrm{T}} \xi\left(\bar{e}_{1}\right)-\varepsilon_{1}\right]+e_{4}\left[\tilde{\theta}_{2}^{\mathrm{T}} \times \xi\left(\bar{e}_{2}\right)-\varepsilon_{2}\right]+\varepsilon_{d 1}+\varepsilon_{d 2}
$$

where $\tilde{\theta}_{2}^{\mathrm{T}}=\hat{\theta}_{2}^{\mathrm{T}}-\theta_{2}^{* \mathrm{~T}} \quad$ is parameter estimation error.

\subsection{Stability Analysis}

Theorem 1: The error variable $\mathrm{e}=\left(\mathrm{e}_{1}, \mathrm{e}_{2}, \mathrm{e}_{3}, \mathrm{e}_{4}\right)$ of the closed-loop system containing controlled object eq.(1), control input eq.(16) and adaptive law eqs.(17), (18) is bounded. Simultaneously, e converges to a sufficient small neighborhood of the origin according to the exponential law.

Proof: We choose augmented CLF $\mathrm{V}_{5}$ as follows:

$$
V_{5}=V_{4}+\frac{1}{2} \tilde{\theta}_{1}^{\mathrm{T}} \Gamma_{1}^{-1} \tilde{\theta}_{1}+\frac{1}{2} \tilde{\theta}_{2}^{\mathrm{T}} \Gamma_{2}^{-1} \tilde{\theta}_{2}
$$

We can calculate the derivative of $\mathrm{V}_{5}$ according to eqs.(17), (18), (20):

$$
\begin{aligned}
\dot{V_{5}} & \leqslant-\sum_{i=1}^{4} k_{i} e_{i}^{2}-e_{2} \varepsilon_{1}-e_{4} \varepsilon_{2}+2 \theta_{1}^{* \mathrm{~T}} \Gamma_{1}^{-1} \hat{\theta}_{1}-2 \hat{\theta}_{1}^{\mathrm{T}} \Gamma_{1}^{-1} \hat{\theta}_{1}+2 \theta_{2}^{* \mathrm{~T}} \Gamma_{2}^{-1} \hat{\theta}_{2}-2 \hat{\theta}_{2}^{\mathrm{T}} \Gamma_{2}^{-1} \hat{\theta}_{2}+\varepsilon_{d 1}+\varepsilon_{d 2} \\
& \leqslant-\sum_{i=1}^{4} k_{i} e_{i}^{2}-e_{2} \varepsilon_{1}-e_{4} \varepsilon_{2}-\frac{1}{2} \tilde{\theta}_{1}^{\mathrm{T}} \Gamma_{1}^{-1} \tilde{\theta}_{1}+2 \theta_{1}^{* \mathrm{~T}} \Gamma_{1}^{-1} \theta_{1}^{*}-\frac{1}{2} \tilde{\theta}_{2}^{\mathrm{T}} \Gamma_{2}^{-1} \tilde{\theta}_{2}+2 \theta_{2}^{* \mathrm{~T}} \Gamma_{2}^{-1} \theta_{2}^{*}+\varepsilon_{d 1}+\varepsilon_{d 2}-k_{0}^{2} A^{2}+k_{0}^{2} A^{2} \\
& \leqslant-d_{0} V_{5}+\varepsilon_{0}
\end{aligned}
$$

where,

$$
d_{0}=\min \left\{2 k_{1}, \frac{2 k k_{2}}{J_{m}}, 2 k_{3}, \frac{2 k_{4}\left(J_{1}+J_{2}\right)}{J_{1} J_{2}}, 2 k_{0}, 1\right\} \varepsilon_{0}=2 \theta_{1}^{* \mathrm{~T}} \Gamma_{1}^{-1} \theta_{1}^{*}+2 \theta_{2}^{* \mathrm{~T}} \Gamma_{2}^{-1} \theta_{2}^{*}+\varepsilon_{d 1}+\varepsilon_{d 2}+k_{0}^{2} A^{2}
$$

Calculating the integral on both sides of eq.(22), we have:

According to eq.(21), we have:

$$
V_{5}(t) \leqslant e^{-d_{0} t} V_{5}(0)+\frac{\varepsilon_{0}}{d_{0}}\left(1-e^{-d_{0} t}\right)
$$

$$
\begin{aligned}
& e_{1}^{2}(t) \leqslant 2 V_{5}(t), \lim _{t \rightarrow \infty} e_{1}(t) \leqslant \sqrt{\frac{2 \varepsilon_{0}}{d_{0}}} \\
& e_{2}^{2}(t) \leqslant \frac{2 k}{J_{m}} V_{5}(t), \lim _{t \rightarrow \infty} e_{2}(t) \leqslant \sqrt{\frac{2 k \varepsilon_{0}}{J_{m} d_{0}}} \\
& e_{3}^{2}(t) \leqslant 2 V_{5}(t), \lim _{t \rightarrow \infty} e_{3}(t) \leqslant \sqrt{\frac{2 \varepsilon_{0}}{d_{0}}} \\
& e_{4}^{2}(t) \leqslant \frac{2\left(J_{1}+J_{2}\right)}{J_{1} J_{2}} V_{5}(t), \lim _{t \rightarrow \infty} e_{4}(t) \leqslant \sqrt{\frac{2\left(J_{1}+J_{2}\right) \varepsilon_{0}}{J_{1} J_{2} d_{0}}}
\end{aligned}
$$


According to almighty approaching theorem, we can suppose $\left|\varepsilon_{1}\right| \leq \mathrm{c}_{2}$ and $\left|\varepsilon_{2}\right| \leq \mathrm{c}_{2}$, where $\mathrm{c}_{1}$ and $\mathrm{c}_{2}$ are both very small positive constants. If the condition of adjustable parameters $\mathrm{k}_{1}, \mathrm{k}_{2}, \mathrm{k}_{3}, \mathrm{k}_{4}$ is chosen, we can choose very small, $\mathrm{c}_{1}, \mathrm{c}_{2}$, $\Gamma_{1}^{-1}$ and $\Gamma_{2}^{-1}$ to ensure that $\varepsilon$ is sufficiently small, which can ensure that the error variable $\mathrm{e}=\left(\mathrm{e}_{1}, \mathrm{e}_{2}, \mathrm{e}_{3}, \mathrm{e}_{4}\right)$ converges to a sufficient small neighborhood of the origin according to the exponential law.

\section{SIMULATION}

System physical parameters are defined in Table 1:

Table 1. System physical parameters.

\begin{tabular}{|c|c|}
\hline$J_{1}, J_{2}$ & $0.185 \mathrm{~kg} \cdot \mathrm{m}^{2}$ \\
\hline $\mathrm{J}_{\mathrm{m}}$ & $0.028 \mathrm{~kg} \cdot \mathrm{m}^{2}$ \\
\hline $\mathrm{b}_{1}, \mathrm{~b}_{2}$ & $1.2 \mathrm{~N} \cdot \mathrm{m} . \mathrm{s} / \mathrm{rad}$ \\
\hline $\mathrm{b}_{\mathrm{m}}$ & $1.3 \mathrm{~N} . \mathrm{m} . \mathrm{s} / \mathrm{rad}$ \\
\hline $\mathrm{k}$ & {$[560+2 \sin (\pi \mathrm{t})] \mathrm{N} \cdot \mathrm{m} / \mathrm{rad}$} \\
\hline $\mathrm{c}$ & $0.15+0.01 \sin (\pi \mathrm{t})] \mathrm{N} \cdot \mathrm{m} / \mathrm{rad}$ \\
\hline$\alpha$ & $0.5 \mathrm{rad}$ \\
\hline
\end{tabular}

In simulation, we choose the design parameters as follows:

$k_{0}=0.8, \mathrm{k}_{1}=5.6, \mathrm{k}_{2}^{\prime}=0.37, \mathrm{k}_{3}=18, \mathrm{k}_{4}^{\prime}=20$.

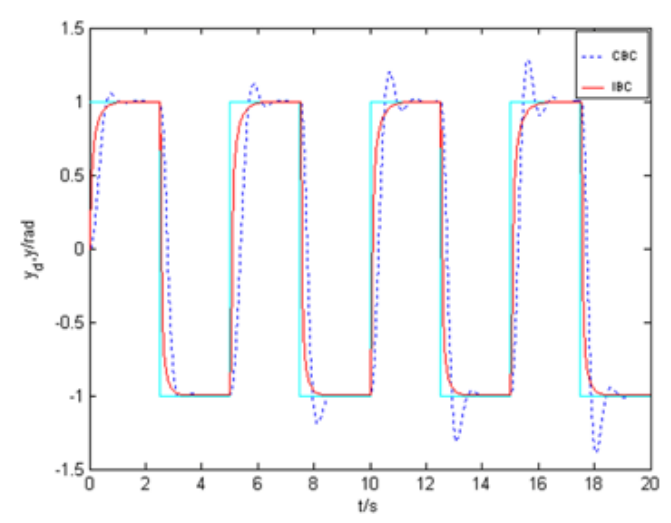

(a) System response for square wave signal.

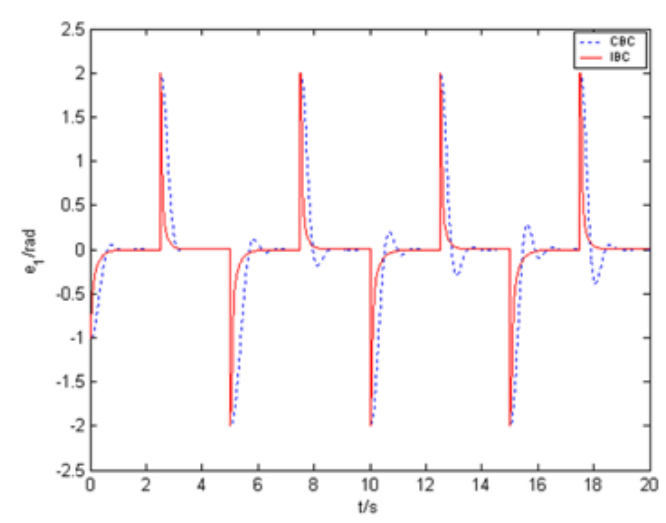

(b) Tracking error for square wave signal.

Fig. (3). System response and tracking error for square wave signal.

The following simulation graphics are the comparison charts of conventional backstepping control(CBC) and the improved backstepping control(IBC).

\subsection{System Response Analysis}

Fig. (3a) is the system response curve for square wave signal input. Fig. (3b) is the tracking error curve for square wave signal.

Figs. (4a \& 5a) are the system response curves for sinusoidal signal input by using $\mathrm{CBC}$ and IBC, respectively. Figs. (4b \& 5b) are the tracking error curves for sinusoidal signal by using CBC and IBC, respectively. From Figs. (3-5), it can be seen that the system has poorer tracking performance and larger tracking error when using CBC. In Fig. (3a), the response overshoot is larger and larger indicating the poorer stability of CBC. But the system can achieve better tracking performance and smaller tracking error when using IBC. 


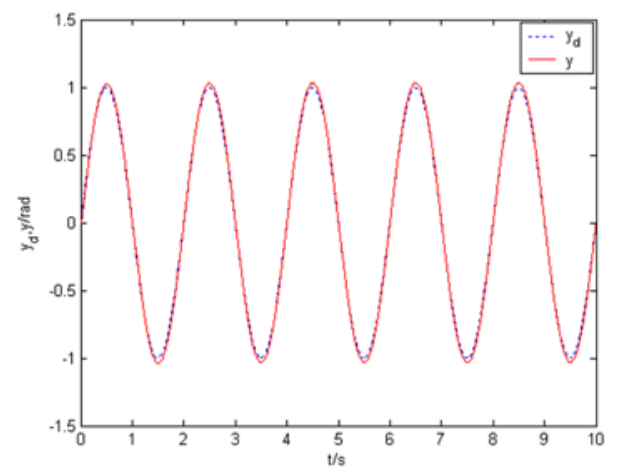

(a) System response for sinusoidal signal.

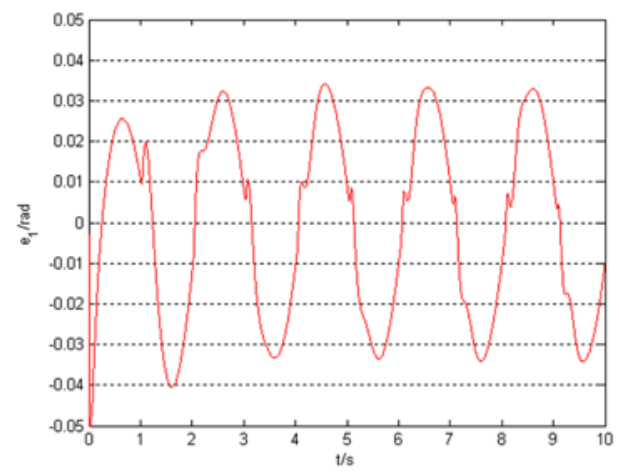

(b) Tracking error for sinusoidal signal.

Fig. (4). System response and tracking error for sinusoidal signal using CBC.

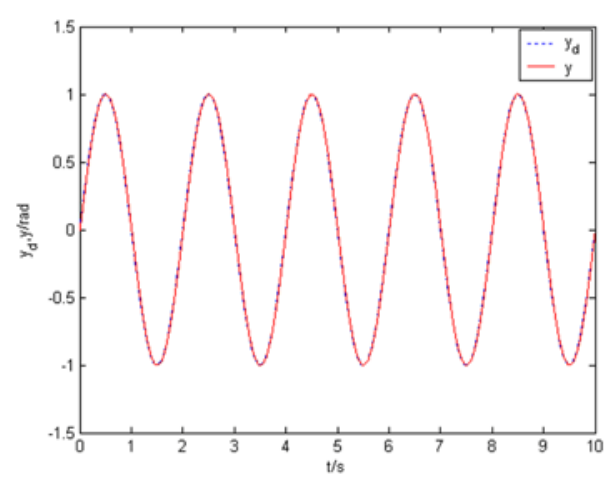

(a) System response for sinusoidal signal.

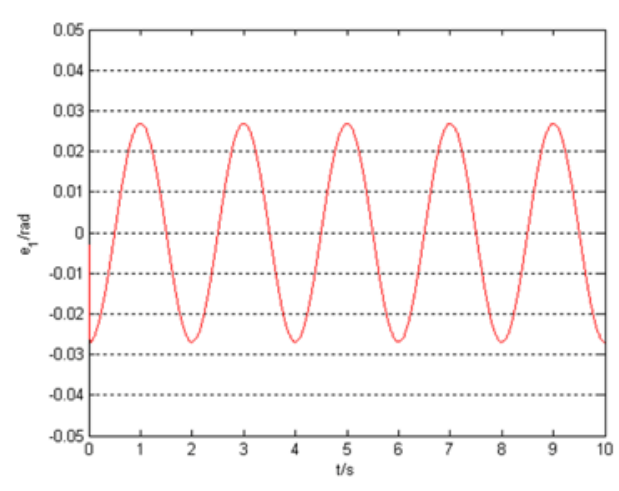

(b) Tracking error for sinusoidal signal.

Fig. (5). System response and tracking error for sinusoidal signal using IBC.

\subsection{System Robustness Analysis}

In Fig. (6), $5 \mathrm{~N} \cdot \mathrm{m}$ disturbance signal is applied to system at $5 \mathrm{~s}$, the system has frequent oscillation process and needs more time to achieve asymptotically stable tracking process again when using $\mathrm{CBC}$. But the system has nearly no oscillation and needs less time to achieve asymptotically stable tracking process again when using IBC. In Figs. (7 \& 8), $20 \mathrm{~N} \cdot \mathrm{m}$ disturbance signal is applied to the system at $5 \mathrm{~s}$, the system not only has a larger fluctuation at $5 \mathrm{~s}$ but also the tracking performance becomes worse after $5 \mathrm{~s}$ when using CBC. But the system tracking performance does not become worse after $5 \mathrm{~s}$, but only has a smaller fluctuation at $5 \mathrm{~s}$ when using IBC. Thus, IBC has better robustness than CBC.

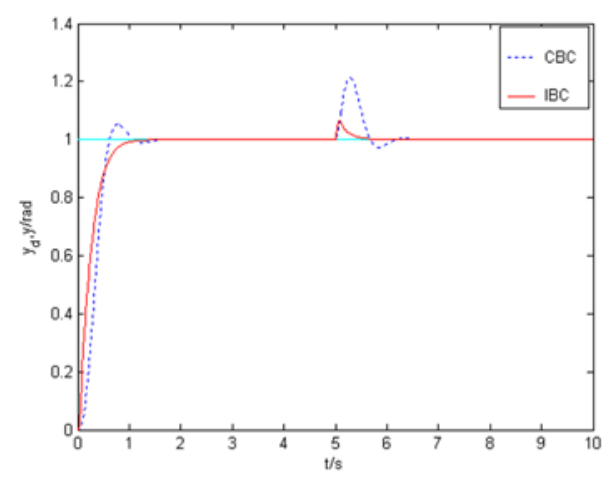

Fig. (6). System step response containing disturbance. 

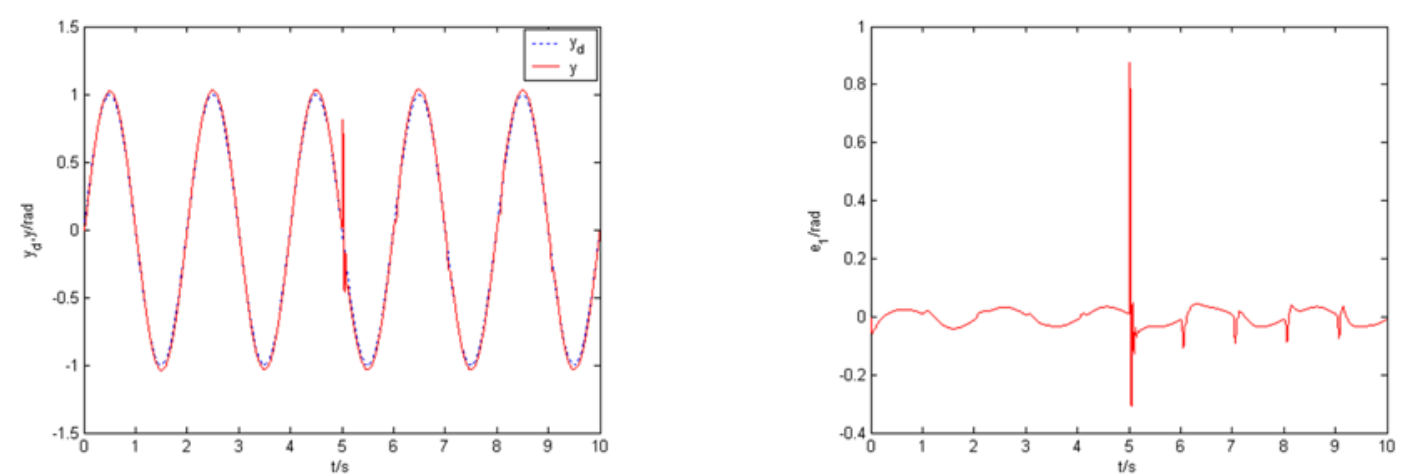

Fig. (7). System response and tracking error for sinusoidal signal using $\mathrm{CBC}$ when disturbance exists.
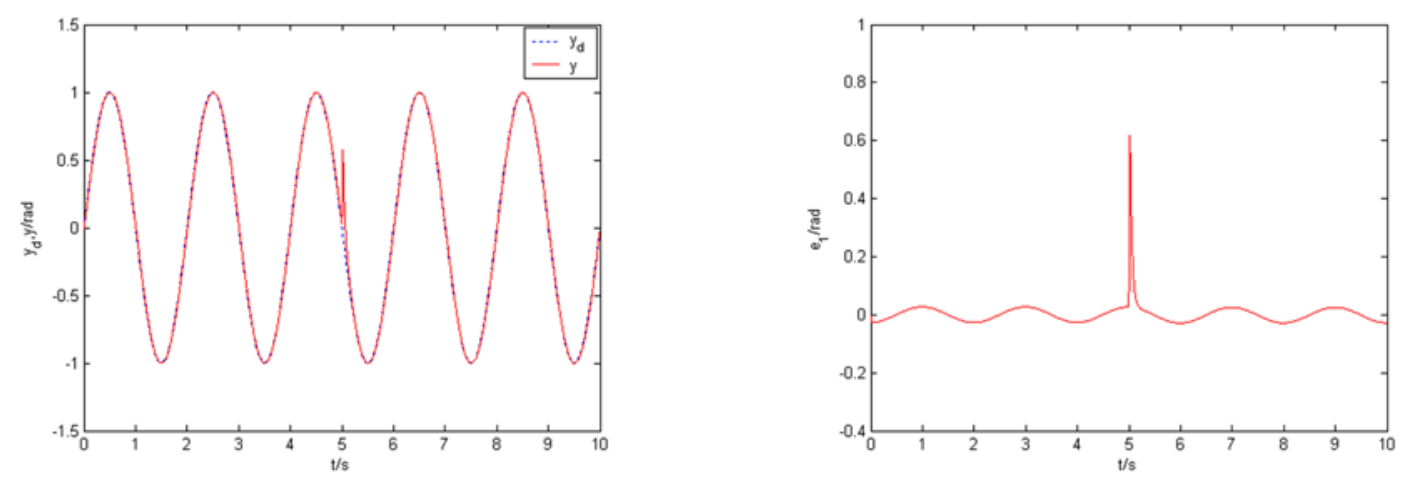

Fig. (8). System response and tracking error for sinusoidal signal using IBC when disturbance exists.

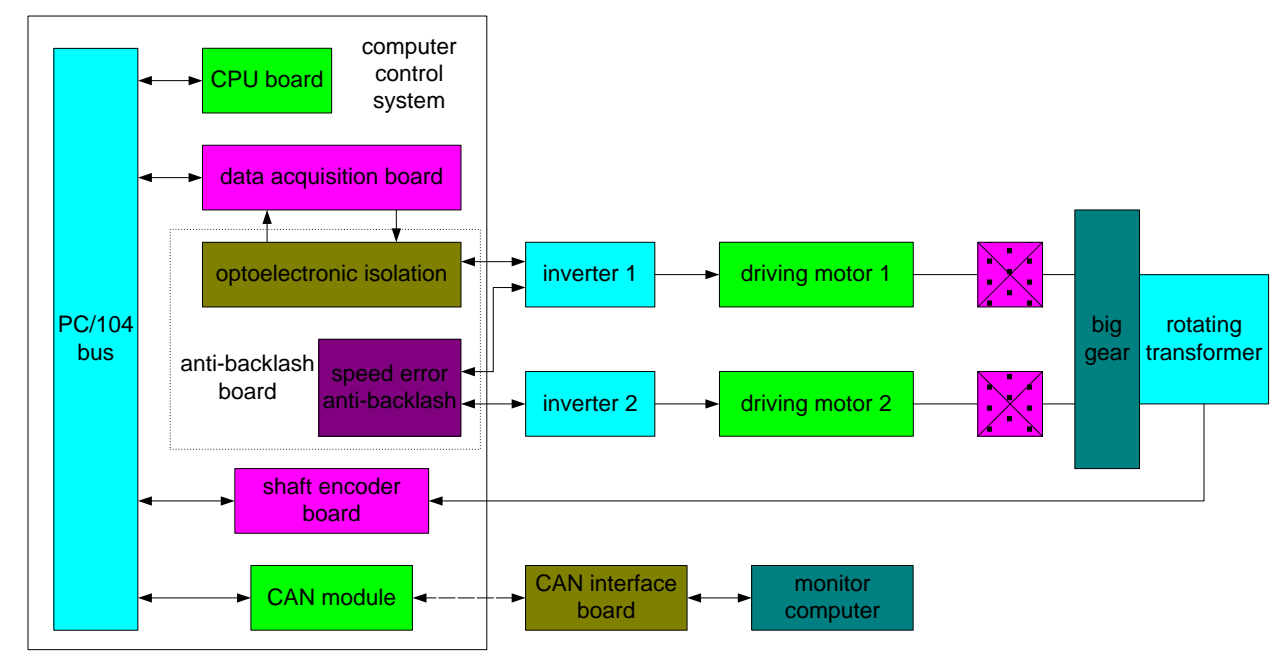

Fig. (9). The overall structure of dual-motor driving servo system.

\section{EXPERIMENTAL ANALYSIS}

The overall structure of dual-motor driving servo system is shown in Fig. (9). Motor is the M-405-C-A1 type produced in Tianjin Cole Morgan Industrial Co., Ltd. Driver is the BDS4 type also produced in Tianjin Cole Morgan Industrial Co., Ltd. Multifunctional data acquisition board is the ADT-700 type. Anti-backlash board and shaft encoder 
board are all self-developed, and domestic shaft encoding chip KXSZ19 is chosen. Rotating transformer is the 110 XFSW008 type. System backlash is $4 \mathrm{mil}$ (mil is angle unit, 360 degree is equal to 6000mil). System performance index is as follows.

1) When step signal input is 1000 mil, overshoot is less than $4 \%$, regulating time is less than $0.8 \mathrm{~s}$, steady state error is less than 10mil;

2)When sinusoidal signal input is $1000 \mathrm{mil} / \mathrm{s}, 1000 \mathrm{mil} /$, steady state error is less than $5 \mathrm{mil}$.

Fig. (10) is 1000 mil step response curve. In Fig. (10a), we can see that overshoot is about 15\%, regulating time is about $1.5 \mathrm{~s}$, the maximum steady state error is about $20 \mathrm{mil}$. But in Fig. (10b), overshoot is about $0.2 \%$, regulating time is about $0.5 \mathrm{~s}$, the maximum steady state error is about $6 \mathrm{mil}$. Fig. (11) is $1000 \mathrm{mil} / \mathrm{s}, 1000 \mathrm{mill} / \mathrm{s} 2$ sinusoidal response error curve. In Fig. (11a), the maximum steady state error is about 7.4mil. But in Fig. (11b), the maximum steady state error is $2.1 \mathrm{mil}$.

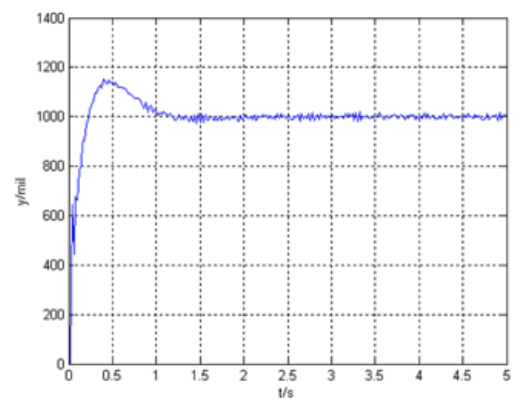

(a) CBC

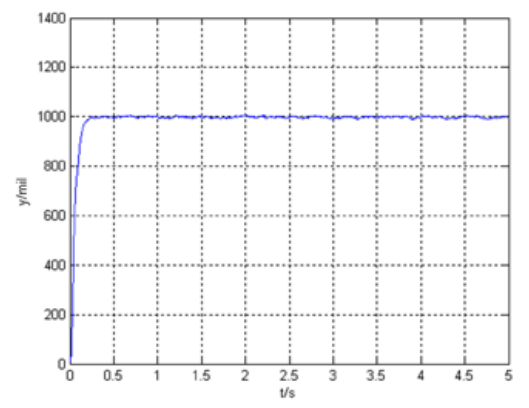

(b) IBC

Fig. (10). Step response curve.

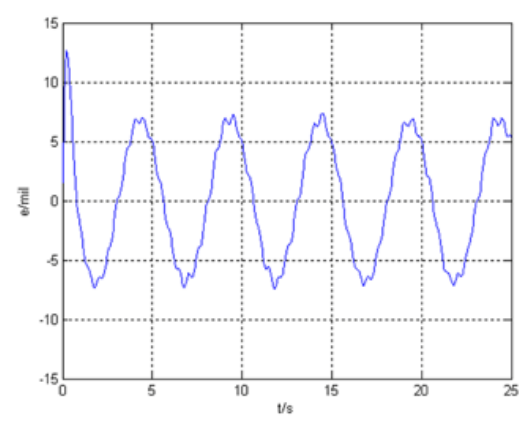

(a) CBC

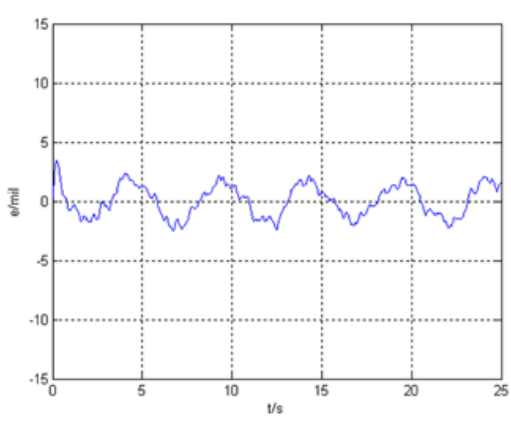

(b) IBC

Fig. (11). Sinusoidal response error curve.

\section{CONCLUSION}

In this paper, the improved backstepping adaptive controller of dual-motor driving servo system with backlash based on fuzzy parameter approximation was designed. Through the analysis of square wave and sinusoidal signal response of system, it can be seen that the system has better tracking performance and smaller tracking error when using IBC. In Fig. (3a), the response overshoot is very small indicating better stability of IBC. In the analysis of system robustness, after the application of disturbance signal to system, it can be seen that the system has smaller oscillation and needs less time to achieve asymptotically stable tracking process again by using IBC. Consequently, the proposed control strategy has the characteristics of higher tracking accuracy, faster response speed, better stability, better robustness and adaptability than conventional backstepping control. But the existence of friction nonlinearity has not been considered in the system. Our future work will be considering the friction nonlinearity. 


\section{STATEMENT OF DISCLOSURE}

The approach used in this article to solve similar motor-control problems have been taken from "Adaptive backstepping fuzzy control for servo systems with backlash," Control Theory \& Applications, vol. 30, no.2, pp. 254-260, 2013.

\section{CONFLICT OF INTEREST}

The authors confirm that this article content has no conflict of interest.

\section{ACKNOWLEDGEMENTS}

This work was supported by National Natural Science Foundation of China(No.61074023), Nature Science Foundation in Anhui Province of China (No.1508085MF130), Natural Science Research Key Project of Universities in Anhui Province of China (No.KJ2015A297), the Engineering Technology Research Center of Optoelectronic Appliance in Anhui Province of China, Sichuan Institute of Aerospace System Engineering in Sichuan Province of China.

\section{REFERENCES}

[1] G.F. Zhao, W.H. Fan, Q.W. Chen, and W.L. Hu, "Survey on backlash nonlinearity", Acta Armamentarii, vol. 27, no. 6, pp. $1072-1080$, 2006.

[2] H. Moradi, and H. Salarieh, "Analysis of nonlinear oscillations in spur gear pairs with approximated modelling of backlash nonlinearity", Mechanism Mach. Theory, vol. 51, no. 5, pp. 14-31, 2012. [http://dx.doi.org/10.1016/j.mechmachtheory.2011.12.005]

[3] S.H. Mousavi, B. Ranjbar-Sahraei, and N. Noroozi, "Output feedback controller for hysteretic time-delayed MIMO nonlinear systems: An Hœ-based indirect adaptive interval type-2 fuzzy approach", Nonlinear Dyn., vol. 68, no. 1, pp. 63-76, 2012. [http://dx.doi.org/10.1007/s11071-011-0204-2]

[4] W.J. Liu, K.K. Shyu, and K.C. Hsu, "Design of uncertain multi-input systems with state delay and input deadzone nonlinearity via sliding mode control", Int. J. Control. Autom. Syst., vol. 9, no. 3, pp. 461-469, 2011. [http://dx.doi.org/10.1007/s12555-011-0305-1]

[5] R.H. Du, Y.F. Wu, W. Chen, and Q.W. Chen, "Adaptive backstepping fuzzy control for servo systems with backlash", Control Theor. App., vol. 30, no. 2, pp. 254-260, 2013.

[6] S. Yang, A. Fafitis, and A. Wiezel, "Nonlinear impact model of a tennis racket and a ball", J. Mech. Sci. Tech., vol. 26, no. 2, pp. 315-321, 2012. [http://dx.doi.org/10.1007/s12206-011-1027-2]

[7] G. Tao, and P.V. Kokotovic, "Adaptive control of systems with backlash", Automatica, vol. 29, no. 2, pp. 323-335, 1993. [http://dx.doi.org/10.1016/0005-1098(93)90126-E]

[8] G. Tao, and P.V. Kokotovic, "Continuous-time adaptive control of systems with unknown backlash", IEEE T. Automatic Control, vol. 40, no. 6, pp. 1083-1087, 1995. [http://dx.doi.org/10.1109/9.388689]

[9] C.Y. Su, Y. Stepanenko, J. Svoboda, and T.P. Leung, "Robust adaptive control of a class of nonlinear systems with unknown backlash-like hysteresis", IEEE T. Automatic Control, vol. 45, no. 12, pp. 2427-2432, 2000. [http://dx.doi.org/10.1109/9.895588]

[10] J. Zhou, C.J. Zhang, and C.Y. Wen, "Robust adaptive output control of uncertain nonlinear plants with unknown backlash nonlinearity", IEEE T. Automatic Control, vol. 52, no. 3, pp. 503-509, 2007. [http://dx.doi.org/10.1109/TAC.2006.890473]

[11] J. Guo, B. Yao, Y.F. Wu, and Q.W. Chen, "Adaptive robust control for a class of nonlinear uncertain system with input backlash", Control Decis., vol. 25, no. 10, pp. 161-166, 2009.

[12] J.O. Jang, and G.J. Jeon, "Backlash compensation of nonlinear systems using fuzzy logic", Int. J. Syst. Sci., vol. 37, no. 7, pp. 485-492, 2006. [http://dx.doi.org/10.1080/00207720600774198]

[13] N.R. Cazarez-Castro, L.T. Aguilar, and O. Castillo, "Fuzzy logic control with genetic membership function parameters optimization for the output regulation of a servomechanism with nonlinear backlash", Expert Syst. Appl., vol. 37, no. 6, pp. 4368-4378, 2010. [http://dx.doi.org/10.1016/j.eswa.2009.11.091]

[14] R.R. Selmic, and F.L. Lewis, "Neural net backlash compensation with Hebbian tuning using dynamic inversion", Automatica, vol. 37, no. 8, pp. 1269-1277, 2001. [http://dx.doi.org/10.1016/S0005-1098(01)00066-8]

[15] D.X. Zhang, J.Y. Jia, and Y.X. Guo, "Neural network sliding mode control approach to backlash and friction compensation", J. Univ. Electron. Sci. Technol. China, vol. 37, no. 5, pp. 793-796, 2008.

[16] J. Vörös, "Identification of nonlinear dynamic systems with input saturation and output backlash using three-block cascade models", $J$. Franklin Inst., vol. 351, no. 12, pp. 5455-5466, 2014. 
[http://dx.doi.org/10.1016/j.jfranklin.2014.09.025]

[17] S. Zhu, M.X. Sun, and X.X. He, "Adaptive control of a class of periodically time-varying nonlinear systems with input backlash", Control Theory App., vol. 29, no. 4, pp. 535-538, 2012.

[18] S. Zhu, M.X. Sun, and X.X. He, "Iterative learning control of a class of nonlinear systems with input backlash", ACTA AUTOMATICA SINICA, vol. 37, no. 8, pp. 1014-1017, 2011.

[19] T. Hanawa, and M.C. Deng, "Compensation on the uncertain nonlinear plants preceded by uncertain backlash", IEEJ Trans. Elec. Inform. Syst., vol. 134, no. 9, pp. 1214-1220, 2014.

[20] N. Takesue, G. Zhang, J. Furusho, and M. Sakaguchi, "Motion control of direct-drive motor by a homogeneous ER fluid", J. Intell. Mater. Syst. Struct., vol. 10, no. 9, pp. 728-731, 2015. [http://dx.doi.org/10.1106/E29D-WQX6-FLTL-VAU2]

[21] M.M. Nezamabadi, and E. Afjei, "A switched reluctance motor for hybrid motion control: design, modeling, and sensorless drive", IET Elec. Power Appl., vol. 10, no. 6, pp. 498-507, 2016 [http://dx.doi.org/10.1049/iet-epa.2015.0548]

[22] W.N. Ma, C. Xu, and Y.J. Guo, "Method of double degrees of freedom backstepping control for position tracking of rocket launcher", Acta Armamentarii, vol. 34, no. 4, pp. 484-489, 2013.

[23] Y.J. Shu, and S. Tang, "Integrated guidance and control backstepping design for blended control missile based on NDO", J. Astronautics, vol. 34, no. 1, pp. 79-85, 2013.

[24] B.L. Geng, Y.A. Hu, J. Li, and Y.T. Zhao, "Prescribed performance backstepping control of uncertain systems with unknown control gains", ACTA AUTOM. SIN., vol. 40, no. 11, pp. 2521-2529, 2014.

[25] Q. Zong, F. Wang, R. Su, and S.K. Shao, "Robust adaptive backstepping tracking control for a flexible air-breathing hypersonic vehicle subject to input constraint", Proc. Inst. Mech. Eng. Part G J. Aerosp. Eng., vol. 229, no. 1, pp. 10-25, 2015. [http://dx.doi.org/10.1177/0954410014525128]

[26] Q. Zhou, H.Y. Li, C.W. Wu, L.J. Wang, and C. Ki Ahn, "Adaptive fuzzy control of nonlinear systems with unmodeled dynamics and input saturation using small-gain approach", IEEE Trans. Syst., Man Cybern. Syst., vol. PP, no. 99, pp. 1-11, 2016. [http://dx.doi.org/10.1109/TSMC.2016.2586108]

[27] H.Y. Li, L.J. Wang, H.P. Du, and A. Boulkroune, "Adaptive fuzzy backstepping tracking control for strict-feedback systems with input delay", IEEE Trans. Fuzzy Syst., vol. PP, no. 99, p. 1, 2016. [http://dx.doi.org/10.1109/TFUZZ.2016.2567457]

[28] Q. Zhou, L.J. Wang, C.W. Wu, H.Y. Li, and H.P. Du, "Adaptive fuzzy control for non-strict feedback systems with input saturation and output constraint", IEEE Trans. Syst. Man. Cybern. Syst., vol. PP, no. 99, pp. 1-12, 2016. [http://dx.doi.org/10.1109/TSMC.2016.2557222]

[29] H.B. Zhao, "Backstepping Adaptive Control of Dual-motor Driving Servo System with Backlash Nonlinearity", In: Proceedings of the 2013 International Conference on Intelligent Control and Information Processing, Beijing, 2013, pp. 655-660. [http://dx.doi.org/10.1109/ICICIP.2013.6568155]

[30] X.W. Guo, Q.J. Wang, and G.L. Li, "Adaptive fuzzy control for permanent magnet spherical motor based on friction compensation", Proc. Chinese Soc. Electr. Eng., vol. 31, no. 15, pp. 75-81, 2011.

(c) Zhao and Wang ; Licensee Bentham Open

This is an open access article licensed under the terms of the Creative Commons Attribution-Non-Commercial 4.0 International Public License (CC BY-NC 4.0) (https://creativecommons.org/licenses/by-nc/4.0/legalcode), which permits unrestricted, non-commercial use, distribution and reproduction in any medium, provided the work is properly cited. 